\title{
Analysis on Forecast Model of Regional Financial Integration
}

\author{
Houqiang Zhou \\ West Normal University, Nanchong, Sichuan, 637002, China
}

Keywords: Financial Integration Level, Model Analysis, Regional Financial Development

\begin{abstract}
Firstly, this paper presents a "two-stage" model measuring the degree of financial integration in a qualitative analysis. The first step of the model distinguishes the over-potential of global and regional financial integration through the setting of a dual model. Then, the new interest series extracted from this model are used as proxy variables of global information impact and regional information impact into the second step of the volatility spillover model to build the correlation between the rate of return of local financial assets and the impact of regional information. Based on the model, two stages of the financial integration of the regional financial integration are respectively measured: the financial integration of the "Guangdong-Hong Kong" special area is analyzed and the impact of the financial crisis and the reform of the exchange rate system on the process of financial integration is discussed.
\end{abstract}

\section{Introduction}

At present, the theory of regional financial development in our country mainly focuses on how regional finance promotes regional economic development. In this regard, a large number of domestic scholars have done a large number of studies, the conclusion is that: the development of regional finance for economic growth have a catalytic role, this effect has long-term effects. However, with the development of regional finance, whether the regional economic gap is narrowing or whether the development of regional finance is accompanied by the increase of regional financial integration, Wei Shangjin said in Pitfalls of a State -dominated Financial System: The Case of China **, using the inter-provincial data to calculate the degree of financial integration in China and comparing with the OECD countries, we think that the degree of integration in China is far below the internal level of OECD countries and the correlation between savings-investment in China is closer Savings between OECD countries --- investment-related. As a result, the capital mobility in China is poor, and the main reason for this phenomenon is the inefficient allocation of resources caused by local government intervention.

\section{Regional financial development}

There are two indicators for measuring financial development, namely, the entire financial-related ratio (FIR), which represents the growth of the total financial sector, and the financial marketability index (FMR), which shows the improvement of financial development efficiency. With regard to the financial-related ratio (FIR), theorists generally use the method proposed by Goldsmith (1969) --- "the ratio between the total amount of existing financial assets and national wealth at one point in time plus the ratio of net foreign assets" To express the level of financial development in a country or region. In most studies, people reduced the calculation of financial-related ratios to the ratio of total financial assets to GDP. In addition, we replace the FMR with RFMR (ie, FMR / SOFI), which relates the ratio of financial marketization to state-owned finance to reflect the degree of competition in financial marketization in various places. Measuring the degree of competition in financial markets solely by the level of financial marketization is not comprehensive, as the overall financial-related ratios vary by region or the state-owned financial-related ratios vary by region. In view of the degree of financial marketization, although the financial-related ratio in Beijing is very high, the degree of marketization in Beijing is the lowest among the seven regions and has been gradually declining since 1993 . The main reason is that its 
state-owned financial-related ratio is too high, meaning that its entire financial assets have a large proportion of assets in China, thus greatly reducing its market efficiency. Similarly, as a financial center with a high financial-related ratio in Shanghai, its degree of financial marketability was not high until 2000. According to Zhou's calculations, the financial-to-deposit-related financial ratios of all financial institutions in Beijing in 1998 were only 27 percentage points higher than the state-owned financial ratios and 35 percentage points higher in Shanghai, both lower than the eastern average, while that in Guangdong was 105 A percentage point. The degree of marketization in Zhejiang has been on the rise, surpassing that of Guangdong since 2000, which is inseparable from the active participation of Zhejiang's private finance and fierce market competition. Thus, since the 1990s, the level of financial development in the seven regions has obviously improved, but there are still differences in the level of development among regions. Guangdong, Jiangsu and Zhejiang provinces opened earlier, with a higher degree of marketization and a markedly faster level of financial development. From Figure 2, we can see once again that the gap between financial market-oriented ratios in the seven regions has expanded significantly since 1997 after going through a gradual decline in 1990-1997 [1].

\section{Comparison of the degree of financial integration in the three major regions}

There are many ways to measure the degree of financial integration, here a country's saving and investment correlation, which is the most commonly used measure of the cross-border capital liquidity at a macro level. The method was proposed by Feldstein and Horioka in 1980 on the basis of the relationship between saving, investment and capital flows. In a closed economy, in the integrated capital market, there is a unified world real interest rate. Savings in any one country are considered as part of a global pool of savings. The increase of a pool of savings in a country should lead to an increase in the world's pool of savings, which will result in increased investment in all countries and investment from different countries Part of a global pool of savings. This means that in an open economy, one country's savings and investment decisions are separated from each other. Countries with high savings rates do not necessarily have high investment rates, while those with low savings rates can have high rates of investment. The correlation coefficient between savings and investment in a country should be very low or even irrelevant. Based on such an understanding, Feldstein and Horioka (1980) proposed using a regression equation to test the openness of a country: $\mathrm{I} / \mathrm{Y}=\mathrm{a}+\mathrm{b}(\mathrm{S} / \mathrm{Y})+\mathrm{e}$ Ratio, $\mathrm{S} / \mathrm{Y}$ for the domestic savings and GNP ratio. Under the premise of integration, $b$ should be zero for small countries, and $b$ for large countries should be close to the proportion of its capital stock. Although the FH test was originally used to measure the degree of financial integration among countries, it can still be used here to test the liquidity of capital in the national area. Generally speaking, the higher the saving-investment correlation is, the lower the degree of financial integration is. On the contrary, the lower the correlation is, the higher the degree of integration is. Here we learn from Wei Shangjin method of calculating China's capital liquidity, using unconditional (Unconditional) savings --- investment-related test and conditional (Conditional) savings-investment correlation test to test the three major regional financial integration The level of the level [2].

In theory and practice, with the development of finance, the degree of integration generally increases. According to Wei Shangjin calculated OECD national saving - investment correlation, the unconditional correlation coefficient of 0 . 56, macroscopical and local policy factors after the separation of the correlation coefficient decreased to 0.28 , which means that the degree of financial integration between these countries increased It's However, the conclusion drawn after the regression of our country 's relevant data is just the opposite. The reasons leading to this phenomenon mainly lie in the following points: 1. Subject to the current financial system and financial policies. At present, there are four state-owned commercial banks in China's financial system, as well as local joint-stock banks and branches of foreign-funded banks. Due to the vertical management and independent operation of banks, plus a two-way system of responsibility (responsible for their superior departments and local governments), in the absence of central bank institutions that provide comprehensive coordination and management of regional finance, Difficult 
to form a more consistent view of the business, which is bound to hinder the realization of financial integration.

In this paper, panel data is used to test the correlation between the 1952-2004 savings in three major regions: investment relevance. The data are mainly from the "New China Statistical Information Compilation" and "China Statistical Yearbook" (1998 --- 2005). Nominal gross domestic product (GDP) per region (province) is broken down into: household and government consumption, total capital formation, stock movements and net exports. Interprovincial savings equal nominal provincial GDP minus private consumption and government spending, and interprovincial investment is equivalent to changes in private and government total capital stock. In this way, the saving rate is equal to the saving ratio on nominal GDP, or SGDP; the investment rate equals the ratio of total capital formation to nominal GDP, ie 1/ GDP [3].

Savings of conditions --- investment correlation test is based on the original data, excluding macro-policy factors and local government under the influence of savings --- the trend of changes in investment-related. Iwamoto and Van Win coop used this method to measure the correlation between savings-investment in Japan's regions. They found that the correlation between the two factors was significantly improved and almost zero. As a result, Japan's regional financial integration is very high. First, we subtract the savings rate and investment rate of the entire region on the basis of the original inter-provincial investment rate and saving rate, namely: $\mathrm{S} *$ it $=$ Sit-S-it (2) $\mathrm{I} *$ it = Iit-I-it) It and Iit are the savings rate and investment rate for province i, S-it is the regional savings rate for province $i$, and I-it is the investment rate for this region except for province i. Second, return the savings-investment ratio after removing the macro-fluctuation and local factors: $\mathrm{S}^{*}$-it $=\alpha \mathrm{i}+\alpha y y i t+\alpha$ FFit + eSit (4) I $*$ it $=\beta \mathrm{i}+\beta$ yyit $+\beta$ FFit + elit Fluctuation or periodicity, smoothing the cyclical fluctuations with HP (100) filtering, ie, yit = HP [log (GDPit)] - HP [log (GDP)]] (6) F represents the intervention of local government, GDP ratio to represent. Finally, the two residual sequences eSit and elit obtained by subtracting the newly generated sequence from the original regression equation are regressed to obtain a new saving-investment correlation coefficient. See Table 3. Under the conditions of savings --- investment correlation decreased significantly, indicating that the government administrative intervention is leading to an important reason for the increase of financial integration. However, judging from the two sub-phases, the correlation coefficient between 1978-1991 and 1992-2004 is still on the rise. For instance, the Beijing-Tianjin-Hebei region rose from 0.47 to 0.67, and the Yangtze River Delta increased from 0.25 To 0.46, which is consistent with the result of unconditional test [4].

\section{Regional economic integration forecast discussion}

The results show that the exchange rate reform has comprehensive impact on the capital market in Guangdong Province. It not only affects the sensitivity of the Guangdong stock index to the impact of Guangdong-Hong Kong information, but also deepens the influence of the global information The extent of the impact. Specifically, after the reform of the RMB exchange rate, there has been a sudden increase. This shows that the reform of the exchange rate system markedly accelerated the process of financial integration between Guangdong and Hong Kong. The process of Guangdong's integration with the global financial system was also hindered by the exchange rate system Reform accelerated. Let us analyze the dummy variables of the two financial crises first. From the perspective of Guangdong-Hong Kong information, the test results are very significant. This shows that the financial crisis has an obvious effect on the financial integration between Guangdong and Hong Kong. However, from the perspective of global information, the first and the coefficient are not significant. It can be inferred from the results that the impact of global information shock on capital markets in Guangdong Province has not changed due to the outbreak of the financial crisis. Given the current development of China's securities market, this result is theoretically acceptable. Overall, the sensitivity coefficient of the unintended rate of return of the Guangdong stock index to the impact of the Guangdong-Hong Kong regional information shows an upward trend over time, which shows that the degree of financial integration between Guangdong Province and Guangdong-Hong Kong region shows a gradual deepening trend . In addition, all 
stages are significantly greater than the degree of integration with the global financial system, Guangdong and Guangdong-Hong Kong financial industry circle integration degree higher, the empirical results are consistent with objective facts. It can be seen from the empirical results that the two-stage model has certain accuracy and credibility in the measurement of financial integration and has been well verified in the empirical studies of Guangdong and Hong Kong [5]. It should be pointed out that the two-step model constructed in this paper is an empirical analysis method based on the capital market price. Strictly speaking, it measures the level and trend of regional financial integration by measuring the degree of integration of capital markets. To more comprehensively measure the degree of regional financial integration, we can make separate estimates from three aspects: money market, bond market and capital market. In data-rich regions, such as the EU countries, the two-step method proposed in this paper can also be applied to measure the degree of integration of the currency and bond markets. However, for the empirical data of Guangdong and Hong Kong, due to the limitation of data, the market makes a similar empirical analysis. However, even though there are some limitations on the data availability, since the ratio obtained by the two-step method has a dynamic character (the available time series, it is still a related quantitative study of financial integration such as financial integration and economic growth Relevance, the determinants of financial integration, etc. provide support and reference.

\section{Conclusions}

Most of the existing studies are aimed at the sovereign states and the quantitative analysis of "Guangdong-Hong Kong" special area is very scarce. The research enriches the research on the financial integration among the "non-sovereign" regions and realizes the innovation in the research object. Since the financial system is the carrier of monetary policy, the financial integration between Guangdong and Hong Kong embodies the degree of cooperation between mainland China and Hong Kong's financial system, and thus determines the effective way of monetary policy between the two places. Therefore, measuring the degree of financial integration between Guangdong and Hong Kong can help the Central Bank to more accurately predict the effectiveness of monetary policy instruments. (3) The level of financial integration affects the pattern and development of the financial industry. The deepening financial integration between Guangdong and Hong Kong helps to improve Hong Kong's financial system's over-reliance on the U.S. dollar and enhance its resilience to external shocks. Therefore, measuring the level of financial integration and tracking the process of financial integration has important reference value for policy makers

\section{References}

[1] He Dexu, Dong Jie. Pattern Selection and Operational Mechanism of Financial Integration of Beijing, Tianjin and Hebei [J]. Journal of Graduate School of the Chinese Academy of Social Sciences 2015 (03): 34-36

[2] Wang Wei, Yang Jiaohui, Sun Dachao. East Asian regional financial integration motivation and resistance analysis [J]. World Economy. 2013 (08): 42-45

[3] Radar, Zhao Yong. Financial Development, Financial Integration and Currency Internationalization Model [J]. Journal of Renmin University of China. 2012 (03): 126-135

[4] Zhg Qian, Yang Gongyan, Liu Hongzhong. Status and Challenges of East Asian Financial Integration: A Study Based on Market Segmentation [J]. Journal of Asia and Pacific Economics. 2012 (05): 93-95

[5] Zhijia Jia. Feasibility of Cross-Strait Financial Integration and Its Path Analysis [J]. Asia-Pacific Economy. 2010 (02): 21-33 